\title{
FRUGAL INNOVATIONS IN INDUSTRY 4.0: THE IDENTIFICATION OF KEY INDICATORS
}

\author{
Sinisa Tesic, Bojana Bajic, Ilija Cosic \& Aleksandar Rikalovic
}
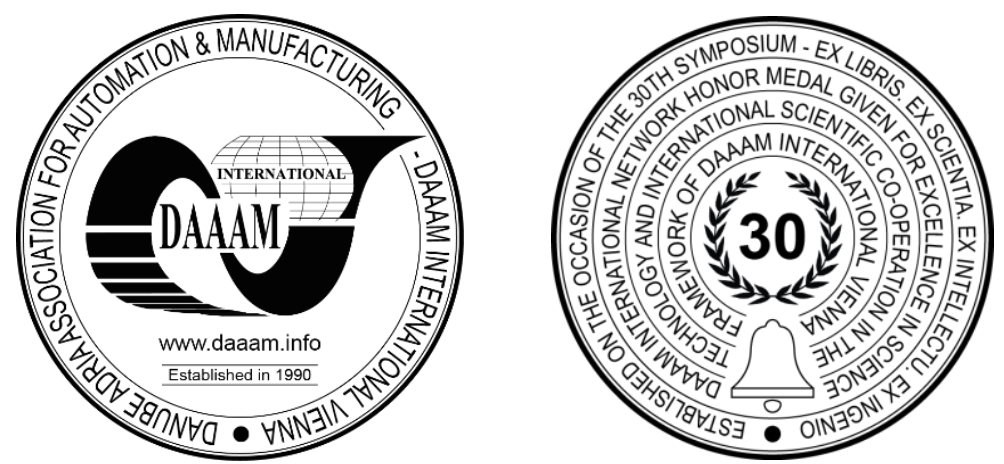

This Publication has to be referred as: Tesic, S[inisa]; Bajic, B[ojana]; Cosic, I[lija] \& Rikalovic, A[leksandar] (2021). Frugal innovations in Industry 4.0: The Identification of Key Indicatiors, Proceedings of the 32nd DAAAM International Symposium, pp.0262-0269, B. Katalinic (Ed.), Published by DAAAM International, ISBN 978-3-902734-33-4, ISSN 1726-9679, Vienna, Austria

DOI: $10.2507 / 32$ nd.daaam.proceedings.037

\begin{abstract}
Innovations refer to the actions required to create new ideas, processes or products. The implementation of new ideas, processes or products leads to positive effective change in a company. The positive effective change in a company is accomplished through savings. Thus, company makes savings in different types of resources via innovations, contribute to social goal or influence the development of technological solutions. In industry, savings via innovations are mostly reflected in redesigning products and processes to cut out unnecessary costs. That type of innovations are called frugal innovations. Frugal innovations represent innovations of existing solutions with accent of achieving resource savings. Nowadays, frugal innovations, which are used in industry, play a vital role in era of fourth industrial revolution, named Industry 4.0. From the innovations point of view, the core of Industry 4.0 is the development of advanced technologies with the goal of achieving savings in processes, products or services The value of frugal innovation analysis in Industry 4.0 represents the contribution of technology transfer in developing countries with the goal of strengthening the competitiveness of companies and the development of new ways of innovations through the impact on society as a form of savings that the company could achieve. Therefore, this paper deals with the analysis of frugal innovations in Industry 4.0 with the goal of the identification of key indicators that have a high influence on their development.
\end{abstract}

Keywords: Frugal innovation; Industry 4.0; Indicators; Cyber Physical Systems (CPS); Industrial Internet of Things (IIoT);

\section{Introduction}

Any positive change in the management, process, production or service in the company is an innovation. Innovation does not have to be a revolutionary invention, it could be a minor change that contributes to the ease of work or makes the process, product or service different from the existing one [1]. However, if the focus is put on savings in resources through innovations which has benefits to society, then we talk about frugal innovations. Frugal innovations represent a process, product or service that arises as savings in finance, human resources, technology or another type of savings where the end result is cheaper solutions than the competitions' which meets customer need [2]. Thus, frugal innovations can be described as innovations that achieve significant savings with minimal investment [3]. 
In the present, the development of frugal innovation is influenced by means of savings in new products, processes, service and business models due to impact of Industry 4.0 era. The fundaments of Industry 4.0 is based on innovations that directly affect the improvement of the company's business. Innovations in Industry 4.0 are related to technological and managerial innovations in the company. The Industry 4.0 concept is driven by Industry 4.0 technology categories, namely: cyber physical systems (CPS), Internet of Things (IoT), big data analytics (BDA), cloud computing, fog and edge computing, augmented and virtual reality (AR/VR), robotics, cyber security, semantic web technologies, and additive manufacturing (AM) [4], in order to improve products, processes, service and business models [5]. The technology categories have emerged as a result of technological innovation. Technological innovations via technology categories in Industry 4.0 have paved the way for prediction, control, maintainance and integration of production processes [6], [7]. However, the recent literature [8], [9], [10] recognized that the frugal innovations in Industry 4.0 are driven by several indicators, namely: the development of the economic environment, enterprise size, sustainability of furgal innovation, the degree of digital transformation in the environment in which the company operates, and so on [8], [9],[11].

Since the relevant literature lack of the observations of frugal innovations from the key indicators point of view in the Industry 4.0, this paper tries to fullfil this gap. That is done by indentifieing and analysing the indicators that influence the development of frugal innovation in Industry 4.0. The development of frugal innovation is based on the needs of the industry for continuous savings, but also on customer requirements for good and affordable products. To answer the question whether the frugal innovations have an impact on Industry 4.0, the paper analyzes the connection between Industry 4.0 and frugal innovation through key indicators. The research questions that this paper is answering are: How frugal innovation contribute to the better development of Industry 4.0 and which indicators influence the development of frugal innovations in Industry 4.0 ?

The rest of the article is organized as follows. Section 2 provides a theoretical background of innovations in Industry 4.0 and frugal innovations. Section 3 presents the identification of key indicatiors of frugal innovation in Industry 4.0 . Section 4 discusses importance of key indicators of frugal innovation in Industry 4.0. Finally, Section 5 provides conclusion and future work.

\section{Background}

\subsection{Frugal innovations}

The history of frugal innovation is linked to Schumacher. He aimed to reduce class differences, not maximize profits. Therefore, its understanding and connection with new technologies have led to a reduction in class differences through the application of frugal innovations. According to Schumacher, the beginning of frugal innovations was associated with the transfer of technology from advanced countries to developing countries, and these innovations, in addition to savings, also contribute to the social goal [10]. However, the transfer of technology based on frugal innovations gained importance in the first decade of the $21^{\text {st }}$ century [12].

Even though, the beginnings of research in the field of frugal innovation was related to developing countries, the recent researches of frugal innovation are recognized as a global potential for development in advanced countries as well. Since 2014, the European Union (EU) has acknowledged the potential of frugal innovations development described in their official document [13]. The EU recognizes the first generation of frugal innovation as an approach to global challenges for certain areas of the economy based on savings and contributing to society goals that rely on advanced technologies [8]. According to the EU [13] some of the features of frugal innovation are reduction of a unit cost, addition of a value of innovation and achievement of the acceptable performance of innovation. An important aspect of frugal innovation is to adjust the achieved savings of innovation and give value to society [14]. Frugal innovation does not necessarily represent the core activity of the company, but can relate to one area or department in the company. If we look at company management, frugal innovation can enhance a company's performance by managing a company based on savings [15] and cutting out business costs [16].

Within the second generation of definitions of frugal innovation, different authors suggest a different perspective and provide a process-oriented definition. In recent times, frugal innovations are seen as significant savings with minimal investments [17]. Finally, the third generation represents a breaking point for frugal innovation and identified three elements that characterize frugal innovation, both in emerging and developed markets: substantial cost reduction, concentration on core functionalities and optimized performance level [18]. Another important research identified three fundamental dimensions of constraint-based innovation: cost-effectiveness, ease-of-use, and prescriptive variables [19].

Frugal innovations can affect economic development by using and adapting developed IT technologies owned by advanced countries in underdeveloped countries. Based on the above, totally new innovative solutions can be developed in advanced countries, which can cause significant changes and lead to disruption of technology [20]. Thus, frugal innovations represent the potential for the development of innovative responsible business of companies. Responsible business of the company means the contribution that the company gives through solving a certain society problem. In addition, frugal innovations should offer innovative solutions based on savings in finance, human resources, or technology, which result in cheaper than the current solutions [2]. If we connect the frugal innovations with production then frugal innovations apply as a change in the way of thinking through the entire production process, i.e. product development. The impact of frugal innovation can be extended, so development of frugal innovation in production represents a change in the mindset of the entire business model [21]. 
The development of frugal innovations can be influenced by various factors in order to be successful. Successfulness of implemented innovation depends of its type. Types of innovation can be distinguished by the use of three indicators, namely sophistication, sustainability and market orientation [22]. Frugal innovation can contain several different types of innovations and most often frugal innovations can include economic innovations, social innovations and technological innovations or their combination [23]. However, the most important characteristic of all types of frugal innovations are savings. Thus, the definition of frugal innovations that is used in this paper focuses on saving, and reads: frugal innovations are innovations that reduce the total cost of the product by eliminating an addition value of the product and opens different perspectives to industries regarding markets.

\subsection{Innovations in Industry 4.0}

Industry 4.0 represents the concept of the fourth industrial revolution that is relevant to the manufacturing sector. Before Industry 4.0, the first three industrial revolutions took place. The first industrial revolution happened at the end of the $17^{\text {th }}$ century, and was initiated by the appearance of steam engines, water power and mechanization. After that, the second industrial revolution was forced by assembly lines and the introduction of mass production by Henry Ford. The third industrial revolution was driven by the use of computers and automation in production processes. Finally, the fourth industrial revolution, known as Industry 4.0, is a concept coined and introduced by the German federal government as an innovative high-tech strategy in late 2011 [22].

The term 'revolution' in the Industry 4.0 concept suggests the existence of a differentiating patterns of product innovation, process innovation and business model innovation. This concept bases on an innovative approach and is driven by the development of digital technology. Digital technology in Industry 4.0 concept brings together the physical parts of a particular production process and the cyber parts through smart networking [24]. Physical parts of the production process consist of machinery, various devices and sensors, while smart networked cyber parts consist mainly of advanced software [24]. Therefore, the current technological benefits in companies are directly connected with Industry $4.0 \mathrm{concept}$ [22].

The development of Industry 4.0 is conditioned by the difficulties of implementation of Industry 4.0 in practice. The challenges of practical implementation of Industry 4.0 represent the potential for the development of innovations in Industry 4.0 that can be divided into managerial and technological challenges [6]. With the development of Industry 4.0, a new form of innovation have developed. Before Industry 4.0, innovations in manufacturing sectors were focused on savings in automation and digitization of production processes. Also, innovations in organization have been developed, but Industry 4.0 has contributed to greater opportunities and a wider range of innovations in management. The possibility of developing innovations in Industry 4.0 depends on technological innovation capability, which includes not only engineerings' capability of utilizing new information technology and operation technology, but also innovation management capability of managing the process of linking market with technological development and strategy [5].

In order to identify all stakeholders in the analysis of frugal innovation and Industry 4.0, it is necessary to identify the framework for action and significant sources of frugal innovation in Industry 4.0. We can identify stakeholders who are interested in frugal innovation and we can divide them into institutions that develop the eco-system of frugal innovations, innovators involved in the process of development of frugal innovations and end users of frugal innovations. Stakeholders in the field of frugal innovation in the Industry 4.0 era could be grouped into:

- Institutions and relations among ecosystem actors - here we identify the role played by institutions, considering both the policy-making level, and the role of education and research institutions in the social context;

- Innovators involved in the frugal innovation process - where we distinguished two levels of innovators:

- Firm-level innovators - innovation involving different types of organizations, such as small, micro, and medium-sized enterprises, as well as multinational enterprises;

- Grassroots-level innovators - innovation involving individuals, informal enterprises, and local communities.

- Consumers - they play a key role as the final beneficiaries of frugal innovations [8].

Industry 4.0 is based on the digitization of industrial value creation, especially connecting vertical and horizontaapproaches in industry that are reflected through the networking of humans, machines, and products [25]. Vertical connectivity refers to the development and management of a company's activities, such as: organizational structure, human factor, departmental relations, technological and management level. Horizontal connectivity includes external relations, establishes the integration of supplier and customer networks, information and management systems[25]. Vertical and horizontal integration will allow industry to identifying gaps and find solution to implement Industry 4.0 concept [26].

The consequences of the Covid 19 pandemic during 2020 influenced the global usage of digital technology. Although, the usage of digital technology increased, the pandemic disabled the daily activities in production companies. This has had the effect of reducing the company's profits and thus the improvements of the company has been lagging behind. This lag slowed down the global development of the company and significantly affected the development of digital technology along with Industry 4.0 concept. Therefore, it is important to learn a lesson from this situation, and to improve the production system in the direction of digital technology development, where the influence of the human factor would be reduced, and the level of system automation would develop in the direction of "self-awareness", "self-predicting", "selfmaintaining" and "self-learning" production [23]. 


\section{Key indicators of frugal innovation in Industry 4.0}

By their definition, the frugal innovations create savings and contribute to socio-economic development, while Industry 4.0 contributes to technological development. The analysis of literature shows that there is a connection between frugal innovations and Industry 4.0 [27], [28]. Their connection is reflected in the creation of savings. Savings are defined through key indicators for the development of frugal innovation in Industry 4.0. However, identifying indicators in the development of frugal innovation in Industry 4.0 is a challenge. The indicators of frugal innovation in Industry 4.0 represent a combination of advanced technologies and social/economics development. By searching the existing literature of the development of frugal innovations in Industry 4.0, we identified 7 indicators (Fig. 1), namely:

- artificial intelligence (AI),

- cyber physical system (CPS)

- industrial Internet of Things (IIoT),

- big data analytics (BDA),

- country development level,

- return of the investment $(\mathrm{RoI})$, and

- a company size.

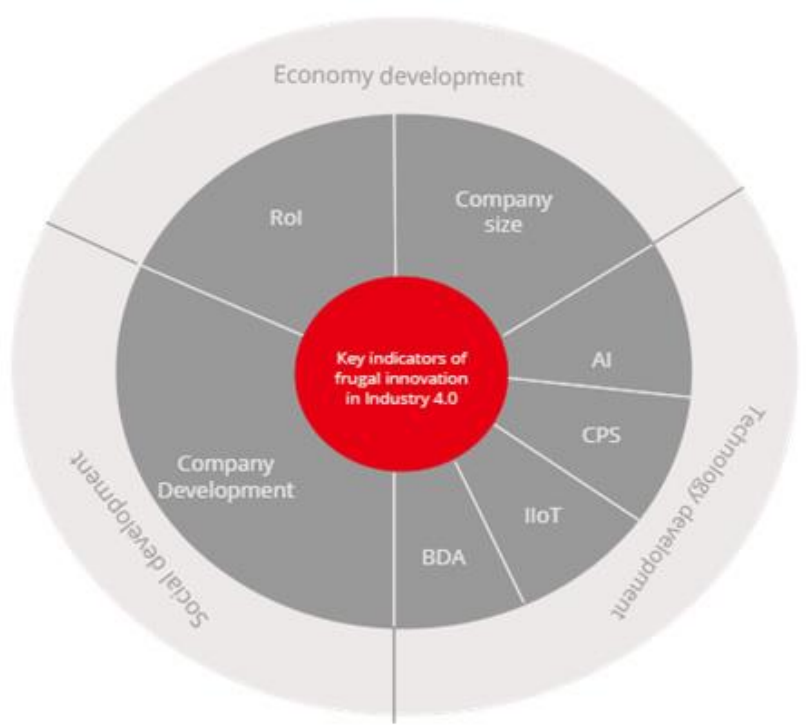

Fig. 1. Key indicators of frugal innovation in Industry 4.0 with their impact on development

Artificial intelligence - AI can be described as giving tasks to computers to solve them that would normally require human intelligence [29]. The member states of the EU are working together on AI to improve their competitive advantages, but AI can be used to advance underdeveloped countries as well. Artificial technologies can be applied as a tool for frugal innovation to solve the problems and challenges that companies are facing with [30]. Rapid development of AI within Industry 4.0 will affect the multiple innovations and creativity which results in health, robotics, computing technology and even automation of various sectors [31]. It can be concluded that AI is an indicator of the development of frugal innovation in Industry 4.0. The sensitivity of the development of frugal innovations within AI can lead to the development of disruptive technologies, i.e. disruptive innovation.

Cyber physical systems - CPS consist of both computational and physical components working together with the goal of implementation of a process monitoring and managing in real time. Thus, CPS is a very important indicator in the development of frugal innovation in Industry 4.0. If we analyze the potential for the development of frugal innovation through the development of CPS at the time of Covid 19, we can see that Industry 4.0 as a goal wants to achieve savings, which is also the goal of frugal innovation. The importance of the transformation of Industry 4.0 in influential innovations is related to the globalization of technologies and innovations, as well as to the interruptions that occur due to technological progress. In the rapid development of Industry 4.0, individualized demand and a small series of production are based on CPS and technology that lead to frugal innovations [32]. Technology and innovation management needs to find new ways related to business models based on savings, quasi-public goods, responsible earnings, digital ecosystems, platform solutions and relevance to competition [33].

Industrial Internet of Things - IIoT is an innovative technology consisting of applications that realize functions and services in a wide range of domains [34]. IIoT connects the physical world with the digital world [35]. IIoT is a collection of smart devices and objects that detect, collect, process and communicate in real time in industrial settings [36].

It leads to resource savings that have a connection with frugal innovation through digitalization and automation of industrial production, organization or process. Rapid development of IIoT, due to the specific requirements of the market and customers, is driven by savings that lead to the development of frugal innovation. However, in the development process there can be major changes, namely development of disruptive innovations. 
Big data analytics (BDA) - big data can be defined as advanced software or mathematical model that has the function to analyze, process and extract information from complex and huge data sets. BDA is associated with three aspects of technical innovation and extremely large data sets: automated parallel computing, data management schemes, and data mining. [37]. The development of BDA has an impact on value creation and savings. The use of big data enables the company to develop efficient and effective innovations [38]. BDA can help company to collect and process market information to better understand consumers' preferences, which can play a critical role in innovation performance. Based on the link between innovation and the savings they make, BDA is an indicator for the development of frugal innovation in Industry 4.0. The ability to develop innovations in the company is one of the possibilities in the use of new sources, such as BDA that contribute to the improved performances of the company [39].

Country development level - indicator for the development of frugal innovation in Industry 4.0 is the level of the country development [40]. The development of frugal innovation depends whether the company is located in developed country or an underdeveloped country. The country's development directly affects the development of Industry 4.0 due to the rather limited development of advanced technologies and smart processes in underdeveloped countries. When a company's production and services move from developed country to underdeveloped country, it poses a threat to the competitiveness of cheap production in underdeveloped country based on cheap labor [5]. Certain research claims that the production revolution will affect the fact that less and less production in the future will be in underdeveloped countries [41]. The development of frugal innovations is influenced by various elements related to the level of country development in which frugal innovations are developed, such as socio-economic characteristics, institutional capacities and elements of the environment. The dependence of frugal innovations in advanced industry is directly related to the level of the country development. The specificity and development of a country that develops frugal innovation have a great influence on frugal innovations.[8]. The need for frugal innovation has been recognized in underdeveloped countries and in developed economies throw the innovation programs which have a focus on saving resource, availability, and sustainability [42].

Return of the investment - RoI represents an important indicator in Industry 4.0 which support sustainability of frugal innovation. High RoI is almost as likely to result from investments in innovation. The development of innovation in companies is often based on technological development. Evaluation of profitability of investments in technological development is realized through RoI analyzes [43]. Industry 4.0 is based on the technological development and sustainability of investments in development and innovation. According to [44] investments in technological development that contribute to innovation in $51 \%$ of cases have a great importance to companies. The investments in technological development that contribute to better productivity of the company are of great importance for the sustainability. Investments in technological development that contribute to innovation and productivity affect the development of frugal innovations in Industry 4.0.

Company size - One of the important indicator of the development of frugal innovation in advanced industries represents the company size that develops frugal innovations. Companies can be divided into micro, small, medium, multinational based on size. There are several factors that determine the company size and one of them is the number of employees in the company. Micro companies have up to 10 employees, small companies up to 50 employees, medium companies between 50 - 250 employees while large or multinational companies have over 250 employees. It is not the same if frugal innovation should be developed in a small company or it wants to be developed by a multinational company that has a special department for innovation development. Multinational companies often implement frugal innovations in developing countries. Based on the research we could identify three types of organizations that influence on frugal innovation: local/micro companies, small and medium enterprises, and multinational enterprises [9].

\section{Discussion}

Frugal innovations are much more discussed from the non-governmental organizations (NGOs) and government agencies perspectives rather than industry. The NGOs emphasize the importance of frugal innovations from the aspect of social savings. The social savings goals have been recognized by national institutions as the potential for practical improvements in society through frugal innovation. During 2020, the Austrian Development Agency piloted a program to support the development of frugal innovation and cooperation with underdeveloped countries (Program: Innovation for a Better World - Advanced Solutions for Sustainable Development). An important element of the Program for the development of frugal innovations is the obligation to include companies that must be the bearers of development.

However, the Creativity Era of business motivates drivers such as hyper-competition, technology disruption and new customer power. Therefore, companies are increasingly looking to achieve growth from new non-core areas, requiring more focus on innovation - especially breakthrough innovation - in order to survive and prosper [45]. Today, the industry bases its improvements on innovations that affect the development of all sectors. Such innovations include technological and non-technological innovations. The industies improvements based on concept of Industry 4.0 focuses on the development of technological innovation but the need for savings affects the development of non-technological innovation in some sectors, e.g. management in the company.

The existing literature does not provide enough information on the impact of frugal innovations in Industry 4.0. On the one hand, analysis of the existing literature and examples from the practice of frugal innovations disscusses that frugal innovations should enable more inclusive development processes and contribute to responsible business [46], [47]. On the other hand, the main goal of the implementation of the Industry 4.0 concept is improvement of the company. 
However, improvements are achieved and realized through savings via innovations, where frugal innovations play a significant role in Industry 4.0. Therefore, viewed from this aspect frugal innovations represent a need for Industry 4.0 development. The significance of indicators regarding frugal innovations is their prediction abilities of future success of a company. Frugal innovations in Industry 4.0 are defined by indicators that contribute to technological, economic and social development that is presented in table 1. This paper recognizes the key indicators of technological development of frugal innovations in Industry 4.0 are: AI, CPS, IIoT, BDA while the social development indicator is country development level and economic development indicators are: RoI and a company size (Fig. 1). Defined key indicators of frugal innovation create value and lead to new trends in the development of Industry 4.0. The value of frugal innovations in Industry 4.0 is defined through the savings that innovation creates and new development trends arise from the synergy of technological, economic and social development that in some cases lead to disruption.

\begin{tabular}{|l|l|l|}
\hline \multirow{2}{*}{ Key Indicators } & Frugal innovation in Industry 4.0 \\
\hline \multirow{4}{*}{ Technological } & AI & The impact of AI on frugal innovation in Industry 4.0 leads to disruptive innovation. \\
\cline { 2 - 3 } & CPS & $\begin{array}{l}\text { The impact of CPS on frugal innovation in Industry 4.0 leads to development of new } \\
\text { technology. }\end{array}$ \\
\cline { 2 - 3 } Social & IIoT & The impact IIoT driven by savings lead to disruptive innovation. \\
\cline { 2 - 3 } & $\begin{array}{l}\text { Country } \\
\text { Development }\end{array}$ & $\begin{array}{l}\text { BDA driven by savings leads to efficiency and effectiveness of the company. } \\
\text { innovations programs. }\end{array}$ \\
\hline \multirow{3}{*}{ Economic } & RoI & $\begin{array}{l}\text { The impact of RoI on frugal innovation in Industry 4.0 leads to greater investment in } \\
\text { frugal innovation. }\end{array}$ \\
\cline { 2 - 3 } & Company size & $\begin{array}{l}\text { The impact of company size in Industry 4.0 leads to different speeds of frugal } \\
\text { innovation development. }\end{array}$ \\
\hline
\end{tabular}

Table 1. The impact of the key indicators of frugal innovation in Industry 4.0

\section{Conclusion}

The frugal innovations have the word innovation in their name, but they behave differently from traditional innovations. While traditional innovations represent improvements to existing solutions without additional impact, the frugal innovations must contribute to savings and represent an improvement over the existing solution. That can be achieved by thorough analysis of an existing solution with addition of an element of the positive cost-effective performances. Nowadays, positive cost-efective preformances are accomplished via advanced technologies of Industry 4.0 concept.

Companies' development of frugal innovations in business models based on Industry 4.0 concept, changes the way of thinking in addition to the innovation advantage. Frugal innovation contributes to the development and advancement of technology as it is often subject to transfer from developed countries to underdeveloped countries. The real profit of a company largely depends on the innovation in that company. In many ways, frugal innovations give the company the opportunity to make a profit in a responsible way based on resource and cost savings.

This paper is considering the impact of Industry 4.0 concept and frugal innovation as well as the importance of indicators that influence the development of frugal innovation in Industry 4.0. In this paper we argue that the Industry 4.0 concept needs frugal innovations in order for progress of savings development, improvement of existing processes and future industry development. The concept of Industry 4.0 in combination with frugal innovations simplifies operations, reducing operating costs, and making products and services available. That is achieved by identifying the key indicators of frugal innovation that enable Industry 4.0 concept. Thus, this paper identifies the key indicators of frugal innovation in Industry 4.0, namely: artificial intelligence (AI), cyber physical system (CPS), industrial Internet of Things (IIoT), big data analytics (BDA), level of the country's development, return of the investment, and company size. The indentified indicators are grouped into three groups depending of the acpect of their contribution of development, namely: technological, economic and social development. The indentified technological development inicators are AI, CPS, IIoT, BDA. The economic development indicators are RoI and a company size. And last, but not the least is social development indicator refering to country development level. Based on the identified key indicators and the aspetc of their contribution, we argue that frugal innovation could give a competitive advantage to the less developed companies over developed companies through savings. In order to develop frugal innovations in Industry 4.0, it is necessary to define an eco-system. An eco-system can be defined as a set of elements that have an impact on frugal innovation in Industry 4.0. Existing literature claims that frugal innovation ecosystems are including local firms, its suppliers, a network of customers and vendors, government agencies, business support services, logistics and delivery providers, alliance partners, and often even rival firms. Eventhough the frugal innovation eco-system is out of scope of this research, it represents a very important aspect of frugal innovation development. Therefore, in future work, an eco-system for the development of frugal innovations in Industry 4.0 will be developed. Frugal innovations in Industry 4.0 represent development potential and a multidimensional phenomenon that affects products, processes, service and business models. The phenomenon of frugal innovation in Industry 4.0 characterizes the development of savings in an innovative way. 
Savings-based innovations represent a great potential for Industry 4.0, but an ecosystem is needed for their development. The ecosystem for the development of furgal innovations in Industry 4.0 in future works will be confirmed from a real-life case study.

\section{References}

[1] Dahlin, K. B. \& Behrens, D. M. (2005). When is an invention really radical?: Defining and measuring technological radicalness, Research Policy, Vol. 34, No. 5, (June 2005), pp. 717-737, 00487333 [2] Simula, H.; Hossain, M. \& Halme, M.(2015). Frugal and reverse innovations - Quo vadis?, Vol. 109., (September 2015) pp. 1567-1572, ISSN: 00113891

[3] Radjou, N. \& Prabhu, J. (2015). Frugal Innovation: How to do more with less, Profile Books Limited, 1781253757, 9781781253755, 29 Cloth Fair London, United Kingdom

[4] Kamble, S. S.; Gunasekaran, A. \& Gawankar, S. A. (2018). Sustainable Industry 4.0 framework: A systematic literature review identifying the current trends and future perspectives, Process Safety and Environmental Protection, Vol., 117., (July 2018) pp. 408-425, 09575820

[5] Lim, C.; Lee, J. H.; Sonthikorn, P. \& Vongbuyong, S. (2020). Frugal innovation and leapfrogging innovation approach to the Industry 4.0 challenge for a developing country, Asian Journal of Technology Innovation, (2020) pp. 1-22, ISSN: 19761597

[6] Lu, Y. (2017). Industry 4.0: A survey on technologies, applications and open research issues, Journal of Industrial Information Integration, Vol., 6., (June 2017) pp. 1-10, 2452414X

[7] Bajic, B.; Rikalovic, A.; Suzic, N. \& Piuri, V. (2020). Industry 4.0 Implementation Challenges and Opportunities: A Managerial Perspective, IEEE Systems Journal, ISSN 1932-8184, pp. 546-559, IEEE Systems Journal · March 2021, 10.1109/JSYST.2020.3023041

[8] Prabhu, J. \& Jain, S. (2015). Innovation and entrepreneurship in India: understanding jugaad, Asia Pacific Journal of Management, (November 2015) pp. 843-868, 02174561

[9] Neal, R. (2018). Funding Frugal Innovation in Global Health: Philanthropy, Aid, and Industry, In: Frugal Innovation in Bioengineering for the Detection of Infectious Diseases, Chavali, A.K. \& Ramji, R. (Ed.), pp. 99-112, 978-3-31966645-7, Springer International Publishing AG, Switzeland

[10] Rosca, E., Reedya, J. \& Bendul, J. C. (2018). Does Frugal Innovation Enable Sustainable Development? A Systematic Literature, Review European Association of Development Research and Training Institutes, The European Journal of Development Research, Vol. 30, No. 1, (Januar 2018) pp. 136-157, ISSN: 09578811

[11] Pisoni, A. B.; Michelini, L. \& Martignoni, G. (2018). Frugal approach to innovation: State of the art and future perspectives, Journal of Cleaner Production, Vol. 171, (January 2018) 107-126, ISSN: 09596526

[12] Kaplinsky, R (2011). Schumacher meets Schumpeter: Appropriate technology below the radar," Res. Policy, vol. 40, pp. 193-203, doi: 10.1016/j.respol.2010.10.003

[13] McGrath, C. H.; Horvath, V.; Baruch, B.; Gunashekar, S.; Lu, H.; Culbertson, S.; Pankowska, P. \& Chataway, J. (2014). The international dimension of research and innovation cooperation addressing the grand challenges in the global context, European Commission, 2014. RR-725-EC

[14] Chaisung, L. \& Takahiro, F. (2019). Frugal innovation and design changes expanding the cost-performance frontier: A Schumpeterian approach, Research Policy, Vol. 48, No. 4, (May 2019), pp. 1016-1029, 00487333.

[15] Bound, K. \& Thornton, I. (2012). Our frugal future: lessons from India's innovation, Available from: https://media.nesta.org.uk/documents/our_frugal_future.pdf Accessed: 2012-07-01

[16] Tjahjana, D.; Manurung, A. H.; Setiadi, N. J. \& Kosasih, W. (2020). Innovation, Digital Business and Frugal Innovation Type, European Journal of Molecular \& Clinical Medicine Vol. 07., (July 2020) pp. 820-831, ISSN: $2515-8260$

[17] Lozanoa, C. V. \& Vijayana, K. K. (2020). Literature review on Cyber Physical Systems Design, Procedia Manufacturing, Vol. 45, (April 2020), pp. 295-300, ISSN: 2351-9789

[18] Sean, T. (2012). High-speed rail, the knowledge economy and the next growth wave, Journal of Transport Geography, Vol. 22 (May 2012), pp. 285-287, ISSN: 09666923

[19] Agarwal, N. \& Brem, A. (2017). The Frugal Innovation Case of Solar-powered Automated Teller Machines (ATMs) of Vortex Engineering in India, Journal of Entrepreneurship and Innovation in Emerging Economies, Vol. 3, No. 2, (October 2017), pp. 115-126, ISSN: 2393-9575

[20] Jucevicius, G.; Sajeva, S. \& Stankevice, I. (2012). Patterns of Strategic Innovation in the Latecomer Economies: Beyond the Frugality, International Conference on Business Management \& Information Systems, No. 1, (January 2012), 2164-263X

[21] Soni, P. \& Krishnan, R.T. (2014). Frugal innovation: aligning theory, practice, and public policy, Vol. 6, No. 1 , (Januar 2014) pp.29-47, ISSN: 1755-4195

[22] Brem, A. \& Wolfram, P. (2014). Research and development from the bottom up - introduction of terminologies for new product development in emerging markets, Journal of Innovation and Entrepreneurship, Vol. 3, No. 1, (December 2014) pp. 3-9, ISSN: 21925372

[23] Ahuja, S \& Chan, Y. (2016). Digital Innovation: A Frugal Ecosystem Perspective, Proseeding of Thirty Seventh International Conference on Information Systems 11-14. December 2016, Dublin Ireland, 978-099668313-5, 
Agerfalk, P. J.; Levina, N. \& Kien, S. S. (Ed.) pp. 1-22, Association for Information Systems, Dublin, https://aisel.aisnet.org/icis2016/

[24] Nikolic, B.; Ignjatic, J.; Suzic, N.; Stevanov, B. \& Rikalovic, A. (2017). Predictive manufacturing systems in Industry 4.0: Trends, benefits and challenges, Annals of DAAAM and Proceedings of the International DAAAM Symposium, 17269679

[25] Müller, J. M. \& Däschle, S. (2018). Business model innovation of Industry 4.0 solution providers towards customer process innovation, Processes, Vol. 6, No. 12, (December 2018), pp. 1-19, ISSN: 222797177

[26] Schumacher, A.; Erol, S. \& Sihn, W. (2016). A Maturity Model for Assessing Industry 4.0 Readiness and Maturity of Manufacturing Enterprises," Procedia CIRP, vol. 52, pp. 161-166, 2016, doi: 10.1016/j.procir.2016.07.040.

[27] Himang, C. (2020). Defining stages of the Industry 4.0 adoption via indicator sets. Engineering Management in Production and Services, Vol. 12, No. 2 (June 2020) pp. 32-55, ISSN 2543-6597

[28] Švarcová, J.; Urbánek, T.; Povolná, L. \& Sobotková, E. (2019) Implementation of R\&D Results and Industry 4.0 Influenced by Selected Macroeconomic Indicators, Vol. 5 (May 2019) pp. 2-14, ISSN 2076-3417.

[29] Hofmann, E. \& Rüsch, M. (2017). Industry 4.0 and the current status as well as future prospects on logistics, Computers in Industry, Vol. 89, (August 2017), pp. 23-34, ISSN: 01663615

[30] Lucci, S. \& Kopec, D. (2016). Artificial intelligence in the 21st century : a living introduction, Mercury Learning and Information, ISBN: 9781523101320 , Dulles, Virginia

[31] Masanja, N. M. \& Mkumbo, H. (2020). The Application of Open Source Artificial Intelligence as an Approach to Frugal Innovation in Tanzania, International Journal of Research and Innovation in Applied Science (IJRIAS), Vol. 5 No. 3 ( March 2020), pp.36-46, ISSN 2454-6194

[32] Kamble, R. \& Shah, D. (2018). Applications of artificial intelligence in human life, International journal of research, Vol. 6 No. 6 (June 2018) pp. 178-188, ISSN: 2394- 3629

[33] Lua, C.; Changb, F.; Rongc, K.; Shi, Y. \& Yu, X. (2020). Deprecated in policy, abundant in market? The frugal innovation of Chinese low-speed EV industry, International Journal of Production Economics. Vol. 225, (July 2020), pp. 1-14, ISSN107583

[34] Tiwari, R. \& Buse, S. (2019). Managing Innovation in a Global and Digital World: Meeting Societal Challenges and Enhancing Competitiveness, SprignerGabler, 978-3-658-27241-8, Switzerland

[35] Perera, C., Zaslavsky, A., Christen, P., \& Georgakopoulos, D. (2013). Context aware computing for the internet of things: A survey. IEEE communications surveys \& tutorials, Vol. 16, No. 1,(May 2013), pp. 414-454, 1553-877X.

[36] Lampropoulos, G.; Siakas, K. \& Anastasiadis, T. (2019). Internet of things in the context of Industry 4.0: an overview, International Journal of Entrepreneurial Knowledge, Vol. 19, No. 1, (January 2019), pp. 4-19, ISSN: 2336-2952

[37] Liao, X.; Faisal, M.; Chang, Q. Q. \& Ali, A. (2020). Evaluating the Role of Big Data in IIOT-Industrial Internet of Things for Executing Ranks Using the Analytic Network Process Approach. Hindawai, Vol.2020, (October 2020), pp.1-7, 8859454

[38] Khalandar, S. A.; Muzamil, S.; Vincent, D. R. \& Rajput D. S. (2019). Chapter 11 - Challenges in Storing and Processing Big Data Using Hadoop and Spark in book: Deep Learning and Parallel Computing Environment for Bioengineering Systems, Sangaiah, A. K. (August 2019) pp. 179-187, Elsevier Inc. 978-0-12-816718-2, St. Louis, Missouri

[39] Ghasemaghaei, M. \& Calic, G. (2020). Assessing the impact of big data on firm innovation performance: Big data is not always better data, Journal of Business Research, Vol. 108, (January 2020), pp. 147-162, ISSN: 0148-2963

[40] Venkatraman, N. V. ; El Sawy, O. A.; Pavlou, P. A. \& Bharadwaj A. (2014). Theorizing Digital Business Innovation: Platforms and Capabilities in Ecosystems, Available at SSRN: https://ssrn.com/abstract=2510111 2014-09-01

[41] OECD (2017). The Next Production Revolution: Implications for Governments and Business, Avilable from: https://www.oecd-ilibrary.org/science-and-technology/the-next-production-revolution_9789264271036-en Accessed: 2017-05-10

[42] Prahalad, C.K. \& Mashelkar, R.A. (2010). Innovation's Holy Grail, Harvard Business Review, Vol., 88., (July 2010). pp. 1-11, ISSN: 00178012.

[43] Roulstone, B. \& Phillips, J. J. (2008). ROI for Technology Projects, Butterworth Heinemann, ISBN: 9780-0-75068588-7, London

[44] Rao, A.; Kaji, J.; Hurley, B.; Bhat, R. \&Khan, A. (2018). The Industry 4.0 paradox Overcoming disconnects on the path to digital transformation, Avaliable from: www.deloitte.com/insights Accessed: 2021-01-18

[45] Lenarduzzi, M. \& Taibi D. (2016). MVP Explained: A Systematic Mapping Study on the Definitions of Minimal Viable Product, Euromicro SEAA, (August 2016), pp.1-8, ISSN: 2376-9505

[46] Granqvist, K. (2017). Policy brief: Funding frugal innovation Lessons on design and implementation of public funding schemes stimulating frugal innovation, INDIGO Policy, Austria

[47] Baud, I. (2016). Moving Towards Inclusive Development? Recent Views on Inequalities, Frugal Innovations, Urban Geo-Technologies, Gender and Hybrid Governance, European Journal of Development Research, Vol. 28, No. 2, ( April 2016), pp. 119-129, ISSN: 17439728 